\title{
Justice and Immigration: The Effect of Moral Exclusion
}

\author{
Justicia e inmigración: el efecto de la exclusión moral
}

Stefano Passini ${ }^{1 *}$, Paola Villano ${ }^{1}$

\begin{abstract}
Numerous media news items suggest on a daily basis that people tend to use harsher criteria when they judge immigrants than members of their own in-group. In the present research project, we were interested in studying individual justice judgments of a violation of a law by an Italian (in-group) or an immigrant (out-group) member and the influence of moral exclusion processes on the assessment. In particular, we examined whether those people who tend to exclude out-groups from their scope of justice will give such biased judgments and will adopt double standards, while inclusive people will not. A total of 255 people evaluated the seriousness of a crime in two different law-breaking scenarios in which the offender's and the victim's nationalities were systematically changed (either Italian or Romanian). Moreover, participants completed a scale measuring the moral inclusion/exclusion of other social groups. As hypothesized, participants who tended to exclude some groups from their moral community judged the Romanian more harshly than the Italian culprit. On the contrary, those people that tended to have a more inclusive moral community did not show any difference in evaluation. In conclusion, the present research highlights the importance of considering the effect of moral inclusion/ exclusion processes on the evaluation of justice events, especially in an intergroup context.
\end{abstract}

\section{Resumen}

Numerosas noticias en los medios sugieren que las personas tienden a usar criterios más severos cuando juzgan a miembros de grupos de inmigrantes que a quienes pertenecen a su propio grupo. Esta investigación tuvo como propósito estudiar los juicios morales que hacen los individuos ante la violación de una ley por parte de un miembro italiano (dentro del grupo) o un inmigrante (por fuera del grupo) y la influencia de los procesos de exclusión moral en la evaluación. En particular, se evaluó si los participantes tienden a excluir a quienes no pertenecen a su grupo, si emitían juicios sesgados y adoptarían una doble moral, mientras que las personas incluyentes no lo harían. Un total de 255 personas evaluaron la gravedad de un crimen en dos escenarios diferentes de violación de la ley en los cuales las nacionalidades del delincuente y de la víctima se cambiaron sistemáticamente (ya sea italiano o rumano). Además, los participantes completaron una escala que mide la inclusión/exclusión moral de otros grupos sociales. Según la hipótesis, los participantes que tienden a excluir a algunos grupos de su comunidad, tuvieron un juicio moral más severo ante los rumanos que ante los italianos. Por el contrario, aquellos que eran más incluyentes, no presentaron ninguna diferencia en el juicio moral y la evaluación de la situación. En conclusión, la presente investigación destaca la importancia de considerar el efecto de los procesos de inclusión/exclusión moral en la evaluación de los eventos de justicia, especialmente en un contexto intergrupal.

\section{Keywords:}

justice; moral exclusion; double standards; immigration; intergroup conflict.

\section{Palabras claves:}

justicia; exclusión moral; doble moral; inmigración; conflicto intergrupal. 


\section{Introduction}

Although it had been a source of migrants to other countries (e.g. America) during the previous centuries, in the last ten years Italy has had to deal with the phenomenon of immigration. The number of immigrants has risen from $1,549,373$ in 2003 to $5,029,000$ as of January 1st, $2017^{1}$. Since the expansion of the European Union (EU), the most recent waves of migration have mainly been Eastern Europeans who replaced the North African populations as the largest immigrant group in Italy. From 2003 to 2017, Romanians increased their presence in the territory by $12.11 \%$ (from 95,039 to 1,151,395), overtaking Albanians and Moroccans as the largest ethnic minority group in Italy. Although Italy does not have such a high percentage of immigrants with respect to its population as compared to other countries (7.5\%, the tenth country with the highest proportion of immigrants in Europe according to Eurostat), the issue of immigration is constantly at the heart of media and political debates (see Passini, 2015) perhaps due to the fact that this is a recent phenomenon.

Starting from this context of intergroup tension, in this study we were interested in researching the issue of justice and violation of laws by Italians and immigrants. In particular, we examined whether Italians use different evaluation criteria (i.e. a double standard) in judging the violations of a law by an Italian (ingroup) or an immigrant (out-group) member. Indeed, some studies (e.g. van Dijk, 2000) suggest that when the culprits are out-group members, people often tend to judge the event more severely than when the culprits are in-group members. This different evaluation should not be considered to be a general trend. That is, not everyone applies such a prejudicial evaluation. In the present research project, we indeed consider the effects of moral exclusion processes on the evaluation of justice, with the idea that those people who tend to exclude out-groups from their scope of justice will give a biased judgment and will adopt double standards, while inclusive people will not (for a review see Jost \& Major, 2001; Sullivan \& Tifft, 2001).

\section{Scope of justice and moral exclusion}

As Van den Bos (2003) pointed out, considering how individuals form judgments of justice is a relevant issue for understanding how people behave in their social environments. Social psychologists define justice as a judgment people make about events and the desire for justice as an important motivator of human social behavior (see Tyler, Boeckmann, Smith, \& Huo, 1997). As relates to justice, three distinct behavior realms may be

1. Data were taken from the official reports of the Istituto Nazionale di Statistica (ISTAT, http://demo.istat.it), that is, the Italian National Statistical Institute. distinguished (Hafer, Conway, Cheung, Malyk, \& Olson, 2012): those related to the distribution of resources or outcomes (i.e. distributive justice, see Deutsch, 1985), those related to decision-making procedures about distributions or outcomes (i.e. procedural justice, see Lind \& Tyler, 1988), and those related to the treatment of those who are affected by decisions (i.e. interactional justice, see (Bies \& Moag, 1986).

However, the literature on social justice has often ignored the fact that people do not always reflect and consider the issues of justice or fairness when they have to make judgments about a specific person or group (Hafer \& Olson, 2003). That is, scholars have mainly examined the forms that justice takes but not whether justice is applied equally to different social groups. In particular, Opotow (1990) has theorized the relevance of the scope of justice, i.e. a psychological boundary for justice, such that "moral values, rules, and considerations of fairness apply only to those within this boundary for fairness, called our 'scope of justice' or 'moral community" (Opotow, 1990, p. 3). The concept of justice has indeed been linked to that of morality and is usually associated with the notions and perceptions of right and wrong (Hafer et al., 2012). Central to this line of thinking is the assumption that people "are born with an innate capacity to care about morality, and they are predisposed to maintain cooperative systems by rewarding those who behave morally and punishing those who do not" (Skitka, Bauman, \& Mullen, 2008, p.1).

A moral community is defined as the group to which the rules of justice apply and it may be either narrow - referring to only a few people such as in-group members - or wide, as far as referring to the whole world community (see Passini, 2011, 2016). Inclusion or exclusion from the moral community is defined as processes of moral inclusion/exclusion. Moral exclusion processes refer to the exclusion of other individuals or groups from one's own moral community, while moral inclusion processes involve the extension of social justice to groups that had formerly been excluded from the scope of justice. As Opotow (2008) has pointed out, we all have finite boundaries for justice, and processes of moral exclusion are ubiquitous in everyday life and in common intergroup relations. For instance, Passini and Morselli (2016) showed that morally exclusive scopes of justice had a predictive effect on more subtle forms of prejudice. In this sense, the construct of moral inclusion/ exclusion may be very useful for understanding intergroup relationships and the perception of justice related to in-group $v s$. out-group members. Indeed, Opotow's theory suggests that people who consider a group to be excluded from their moral community should judge violation of a law by a member of this group more harshly than the same violation by an in-group member. On the contrary, people who include a group within their moral community should judge the violation of a 
law the same regardless of the group membership of the person who is being judged. As Hafer and Olson (2003) have pointed out, certain variables such as perceived similarity with other groups influence the psychological boundary within which people believe that the rules of justice apply. Some research has indeed found effects of the perception of similarity or dissimilarity with the target group on prejudice or forgiveness. For instance, studies based on social distance theory (Bogardus, 1933) have suggested that the more groups are perceived as distant the greater the risk of attitudes of prejudice and discrimination towards them (e.g. Fontanella, Villano, \& Di Donato, 2016; Norcini Pala, Villano, \& Clinton, 2017; Passini \& Villano, 2013; Stephan \& Stephan, 2001).

The aim of the present study was to analyze the influence of moral inclusion/exclusion processes on individual judgments concerning a law violation by an in-group vs. an out-group member. Participants were presented with various scenarios in which offender and victim nationalities were systematically changed. Because it's the largest immigrant group in Italy, Romanian was chosen as the out-group nationality. Specifically, it was hypothesized that participants with exclusionary attitudes towards other groups from the moral community would evaluate offenders differently based on their nationality (harsher for Romanians) while participants with attitudes of inclusion of the other groups would not.

\section{Methods}

\section{Participants}

Participants were contacted via the Internet. An online questionnaire was constructed using Limesurvey, a survey-generating tool (http://www.limesurvey. org). The questionnaire was publicly accessible and an invitation with the link to the questionnaire was emailed to potential participants by various methods (e.g. mailing lists, newsgroups, and social networking services). Moreover, so-called "snowball sampling" was used: i.e., a non-probability sampling technique where the participants were asked to re-send the questionnaire link to their acquaintances in order to recruit other participants. All the participants were informed that their contribution was voluntary (i.e., no fee was offered) and that their responses would be anonymous and confidential. The questionnaire was written in Italian. In order to check and prevent a person from reentering the survey site, the subjects' IP addresses were monitored. That is, when two or more IP addresses were the same, the socio-demographic data were inspected in order to identify and remove duplicates. No case was found to meet these criteria and therefore no participant was removed. The data were collected in 2016.

A total of 255 Italian citizens (68.2\% women) responded by accessing the website and filling out the questionnaire. Participant ages ranged from 18 to 72 years old $(M=33.68, S D=13.58)$. They were mainly born in the north of Italy (53.8\%), while $37.2 \%$ and 9.1\% came from the center and the south, respectively. As regards their level of education, $7.5 \%$ declared they had finished middle school, $58.7 \%$ declared they had obtained a high school diploma, 33.1\% had a university degree and $0.8 \%$ had a master's or Ph.D. qualification. In terms of employment, $36.7 \%$ stated they were university students, $26.1 \%$ were white collar workers, $11.4 \%$ were teachers, $8.9 \%$ were self-employed, $7.3 \%$ were factory workers/craftsmen, $3.3 \%$ were unemployed, $2.9 \%$ were retired, and finally, 3.4\% chose "other."

\section{Procedure}

Participants were first asked to read two news items, both taken from recent events and adapted for the research project. As can be seen in Appendix, the first news item concerned a person being run over and killed by a drunk driver (drunk driver), while the second concerned a person who had died after a violent argument following a trivial dispute over a bus ticket (violent argument). Therefore, both scenarios involved manslaughter (i.e. an accidental killing) and under Italian law they are considered as equivalent in terms of culpability and the sentence imposed. The present study sought to make participants judge similar crimes in which the offender and the victim were different as concerns in-group and out-group membership. In this sense, the offender and the victim of the two news items were varied so that half of the participants responded to drunk driver with an Italian as the offender and a Romanian as the victim and to violent argument with a Romanian as the offender and an Italian as the victim. The other half of the participants had the nationalities reversed. The text was accompanied by a photo of the offender. The photos were taken from an internet search for average-looking Italian and Romanian men in their thirties.

Participants were asked to answer the following questions on a 7-point scale (from $1=$ "not at all" to 7 = "very much"): (1) how serious do you consider this offense to be? (seriousness); (2) how much anger do you feel towards the culprit? (anger) Additionally, participants were asked to write the number of years of imprisonment they would give the culprit, answering the question: (3) how many years of imprisonment should be given for this offense? (penalty). After that, participants were asked to answer the following measure.

Moral inclusion/exclusion of other groups (MIEG). The moral inclusion/exclusion scale constructed by Passini and Morselli (2017) was used. Participants were first asked to list from 2 to 4 ethnic/cultural groups other than their own that lived in their neighborhood. Subsequently, the MIEG items were applied to the listed groups. The most frequently named groups were Romanians $(f=100)$, Moroccans $(f=80)$, Albanians $(f=59)$ and Chinese $(f=58)$. Then, for each group 
respondents were asked to choose where their position lay on a scale between two statements, the first of which identifying the group's moral exclusion, with the second identifying the group's moral inclusion. The items were bipolar, rated on a 7-point scale between +3 (moral exclusion) on the left and +3 (moral inclusion) on the right. The score was rescaled from -3 (indicating the most agreement with the moral exclusion statement) to +3 (indicating the most agreement with the moral inclusion statement). An example of exclusion is "I think that members of this group of people are extremely uncivilized" versus "I think that members of this group of people are extremely civilized." In the original study, both an exploratory and a confirmatory analysis suggested a one-dimensional solution (see Passini \& Morselli, 2017).
A single score was therefore computed as the average of the four items for all the ethnic/cultural groups chosen by each participant $(a=.95)$. Participants were classified as having a more inclusive attitude towards the groups considered based on a higher MIEG score.

\section{Results}

A chi-square test revealed no interaction between the participants' gender and their nationality: $\chi 2(1, \mathrm{~N}=$ $255)=0.16, p=$ ns. As shown in Table 1 , in general the subjects considered the drunk driver news item more serious than the violent argument. They hoped for a lengthier prison sentence for the drunk driver, and this story generated more anger.

Table 1.

Means and T-Test differences for scenario and offender's nationality among scenario variables.

\begin{tabular}{|c|c|c|c|c|c|c|c|c|}
\hline \multirow[b]{2}{*}{ Measures } & \multicolumn{4}{|c|}{ Scenario } & \multicolumn{4}{|c|}{ Nationality } \\
\hline & $\begin{array}{c}M \\
\text { Drunk Driver }\end{array}$ & $\begin{array}{c}M \\
\text { Violent Argument }\end{array}$ & $t$ & $d$ & $\begin{array}{c}M \\
\text { Italian }\end{array}$ & $\begin{array}{c}M \\
\text { Romanian }\end{array}$ & $t$ & $d$ \\
\hline Seriousness & 6.53 & 5.93 & $9.10 * * *$ & .84 & 6.24 & 6.22 & 0.39 & .04 \\
\hline Anger & 5.48 & 5.20 & $2.79 * *$ & .26 & 5.32 & 5.37 & -0.48 & -.04 \\
\hline Penalty (years) & 19.69 & 15.86 & $2.97 * *$ & .29 & 16.15 & 19.39 & $-2.50 * *$ & .24 \\
\hline
\end{tabular}

Note. Seriousness and anger extended from 1 to 7 . Penalty (years) extended from 0 to 100 .

$* * * p<.001 . * * p<.01 . * p<.05$.

A two-way (Scenario: drunk driver vs. violent argument) ANCOVA with MIEG as a covariate was performed on each item (see Table 2). The interaction Scenario $\times$ MIEG was slightly significant on seriousness and penalty. ${ }^{2}$ A further inspection of the interaction between either low or high MIEG scores (i.e., scores 1 SD below and above the mean, respectively) showed that in both cases people with a low MIEG attitude score tended to evaluate the drunk driver more harshly than the violent argument episode: [seriousness: $\mathrm{t}(37)=4.94, \mathrm{p}<.001$, $\mathrm{M}$ drink-driver $=6.68, \mathrm{M}$ violent argument $=5.63$; penalty: $\mathrm{t}(37)=1.93, \mathrm{p}=.06, \mathrm{M}$ drink-driver $=30.13, \mathrm{M}$ violent argument $=19.35$ ]. Conversely, participants with a high MIEG attitude score did not make any significant difference in evaluating them [seriousness: $\mathrm{t}(32)=1.86$, $\mathrm{p}=\mathrm{ns}, \mathrm{M}$ drink-driver $=6.62, \mathrm{M}$ violent argument $=$ 6.38; penalty: $\mathrm{t}(26)=1.24, \mathrm{p}=\mathrm{ns}, \mathrm{M}$ drink-driver $=$ 23.52, $\mathrm{M}$ violent argument $=22.11]$.

Table 2.

Two-way ANCOVAs of scenario and nationality with MIEG as a covariate.

\begin{tabular}{|c|c|c|c|c|c|c|}
\hline & \multicolumn{2}{|c|}{ Seriousness } & \multicolumn{2}{|c|}{ Anger } & \multicolumn{2}{|c|}{ Penalty (years) } \\
\hline & $\mathrm{F}$ & $\eta 2$ & $\mathrm{~F}$ & $\eta 2$ & $\mathrm{~F}$ & $\eta 2$ \\
\hline Scenario (S) & $19.10 * * *$ & .08 & $4.19 *$ & .02 & $9.70 * *$ & .05 \\
\hline MIEG & 0.66 & .00 & 1.38 & .01 & 1.63 & .01 \\
\hline$S \times M I E G$ & $4.84 *$ & .02 & 1.93 & .01 & $5.79 *$ & .03 \\
\hline Nationality (N) & 10.18 ** & .04 & $10.47 * * *$ & .05 & $27.20 * * *$ & .12 \\
\hline MIEG & 0.66 & .00 & 1.38 & .01 & 1.63 & .01 \\
\hline $\mathrm{N} \times \mathrm{MIEG}$ & $10.99 * * *$ & .05 & $10.48 * * *$ & .05 & $21.18 * * *$ & .10 \\
\hline
\end{tabular}

Note. MIEG = Moral inclusion/exclusion of other groups. Seriousness and anger extended from 1 to 7 . Penalty (years) extended from 0 to 100.

$* * * p<.001 . * * p<.01 . * p<.05$.

2. The analysis was performed including the level of education as well. No significant principal effect of education (seriousness: $F=0.17, p=$ ns, $\eta 2=.00$; anger: $F=0.91, p=n s, \eta 2=.00$; penalty: $F=0.84, p=n s, \eta 2=.00$ ) nor interaction with the scenario (seriousness: $F=2.10, p=n s$, $\eta 2=.01$; anger: $F=1.50, p=\mathrm{ns}, \eta 2=.01$; penalty: $F=0.68, p=\mathrm{ns}, \eta 2=.00$ ) was found. 
By comparing the offender's nationality regardless of the specific scenario (and thus considering the two scenarios as equivalent), data regarding each nationality were analyzed. Seriousness and anger were not significantly different, while participants tended to give a longer prison sentence to the Romanian offender (see Table 1).

A 2 way (nationality's offender) ANCOVA with MIEG as a covariate was performed on each item (see Table 2). The interaction between offender's nationality and MIEG was significant on all the items. ${ }^{3} \mathrm{~A}$ further inspection of the interaction between either low or high MIEG scores (i.e., scores 1 SD below and above the mean, respectively, see Figure 1) showed that, as we predicted, people with low MIEG attitude scores tended to evaluate Romanians more harshly than Italian offenders: seriousness $[t(37)=-2.49, p<.01$, $M$ Italian $=5.84, M$ Romanian $=6.47]$; anger $[\mathrm{t}(35)=$ -2.02, $\mathrm{p}<.05, M$ Italian $=5.00, M$ Romanian $=5.72]$; penalty (years) $[t(36)=-2.63, p<.01, M$ Italian $=$ 17.68, $M$ Romanian $=31.81]$. On the other hand, participants with high MIEG attitude scores tended to evaluate Italian offenders with more seriousness $[t(33)$ $=2.36, p<.05, M$ Italian $=6.56, M$ Romanian $=6.15$ ] and did not make any difference in evaluating anger $[t(30)=1.87, p=\mathrm{ns}, M$ Italian $=5.13, M$ Romanian $=4.81]$ and penalty $[t(26)=0.93, p=n s, M$ Italian $=$ 23.33, $M$ Romanian $=22.30]$.

\section{Discussion}

The aim of this study was to consider the influence of processes of moral inclusion and exclusion on individual judgments of a legal violation by an in-group $v s$. an out-group member. The first result concerns the evaluation of the two news items regardless of the offender's nationality. Even though Italian Law considers the two events as similar given the fact that they both involve a death caused by an accident, participants consider the event involving the drunk driver to be more serious and consequently expect it to result in more years of imprisonment. We can assume that the different evaluation of the two scenarios can be attributed to the fact that recently, the topic of driving after drinking alcohol has been frequently debated in the Italian media. This may have led participants to be less tolerant in judging this event. It is worth noting that the interaction with MIEG shows that participants with exclusionary attitudes tend to have this different judgment of the two scenarios, while more inclusive

3. The analysis was performed including the level of education as well. No significant principal effect of education (seriousness: $F=0.17, p=n s, \eta 2=$ .00 ; anger: $F=0.91, p=\mathrm{ns}, \eta 2=.00$; penalty: $F=0.84, p=\mathrm{ns}, \eta 2=.00$ ) or interaction with nationality (seriousness: $F=3.45, p=n s, \eta 2=.02$; anger: $F=$ $0.43, p=n s, \eta 2=.00$; penalty: $F=1.80, p=n s, \eta 2=.01$ ) was found.
Figure 1.

Offender's nationality $\times$ MIEG interaction among scenario variables.
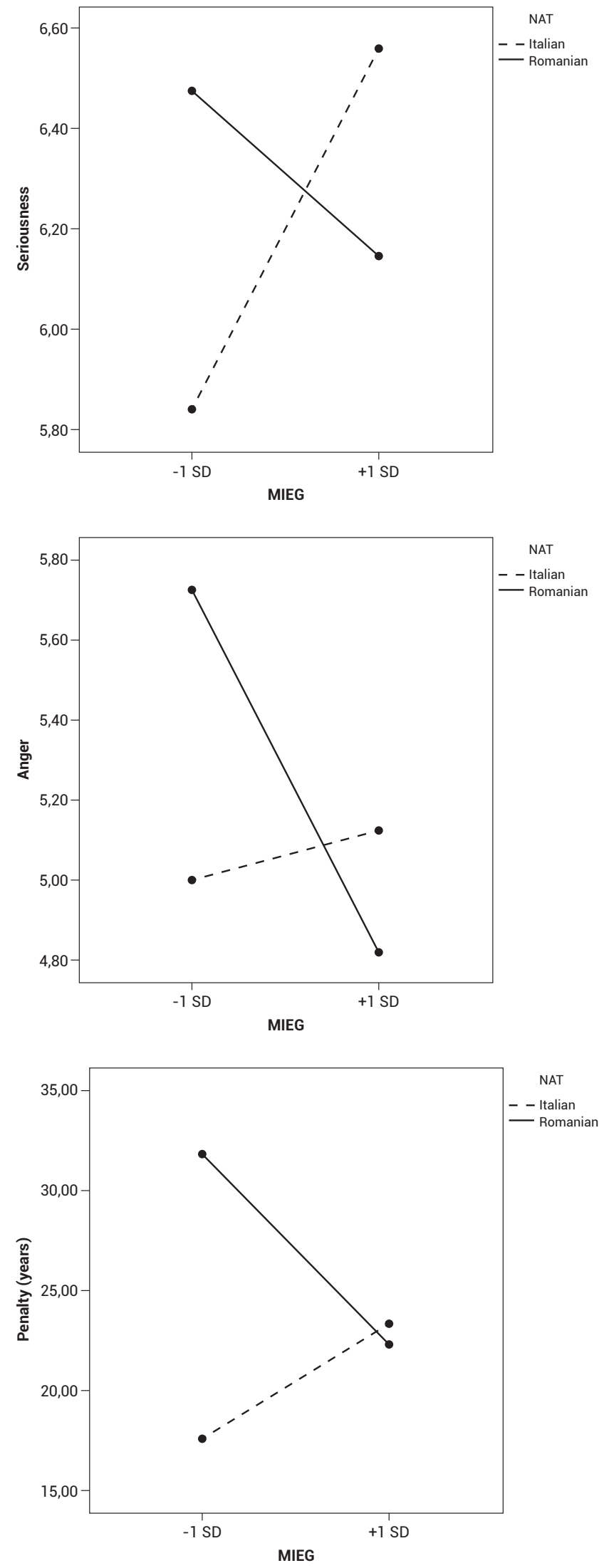
participants do not. We assume that the effect of the public debate on increasing criminal sentences for the event involving the drunk driver is stronger for those who tend to have narrower moral boundaries and be more conformist and aligned with the in-group's collective opinion (see Passini, 2016).

Secondly, as concerns the offender's nationality, the results show that in general participants do not judge the actions of a Romanian to be more serious compared with an Italian, and nor do these invoke more anger. A significant effect was found only on the number of years of imprisonment for the offender. That is, participants expect a stiffer punishment for Romanians. In general, results for all the participants reveal that people do not tend to evaluate the ingroup/out-group scenarios differently, even if they tend to expect stiffer sentencing. This may indicate a desire to avoid being negatively labeled as expressing exclusion by way of a two-fold strategy: apparently evaluating the in-group and out-group equally and then subsequently applying harsher punishments to the out-group lawbreakers.

Thirdly, the consideration of the moral inclusion of the other group variable more clearly shows the effect of nationality on all the questions concerning both scenarios. As we hypothesized, those people who tend to exclude some groups from their moral community indeed judge the Romanian more harshly than the Italian culprit. In line with other studies (Abrams, Randsley de Moura, \& Travaglino, 2013), this result highlights the existence of a double standard of evaluation used by people with exclusionary attitudes, by which they exhibit a greater tolerance for transgressions committed by in-group culprits than out-group culprits. This is in line with Lima-Nunes, Pereira, and Correia (2013) who have found greater support for discrimination policies against immigrants when a restricted scope of justice was considered and when a belief in a just world was made salient. The effects of exclusion may indeed be influenced by perceived deservingness as well, by which groups included in the scope of justice may be seen as more deserving of positive treatment than those who are excluded or perceived as dissimilar (Hafer \& Olson, 2003).

On the contrary, those people who tend to have a more inclusive moral community do not exhibit any difference in their evaluation, though they consider the event with the Italian offender to be slightly more serious. This result may be explained by the so-called "black sheep effect" (Marques, Yzerbyt, \& Leyens, 1988), by which in-group deviants are derogated more than out-group deviants. This is not to say that out-group members are not negatively evaluated. However, we can suppose that inclusive people expect in-group members to be more virtuous than out-group members because they are considered as models of behavior. In some cases, this could produce a less favorable evaluation of in-group offenders because of the violation of such an expectation (see (Abrams, et al., 2013).

Results related to the interaction between individual moral boundaries and the offender's nationality are very important as they demonstrate the importance of considering how people apply justice to different social groups. People may indeed have a separate conception of justice for in-group vs. out-group members, which would have serious consequences for their objectivity in evaluating events. Indeed, people may focus more on certain elements (like nationality) that are not de facto relevant for the evaluation of that event. Moreover, it is worth noting that in the two scenarios the in- or outgroup status of both the offender and the victim were changed. As a result, the effect of moral inclusion/ exclusion on the judgment of the event may also depend on a different feeling of empathy experienced towards in- or out-group victims. Although we did not investigate these scenarios, we can assume that participants with exclusionary attitudes would judge the event involving an out-group offender and an ingroup victim more harshly than when offender and victim are both out-group or in-group members. Indeed, in the former case the effects of both anger towards the out-group offender and solidarity with the in-group victim are added together.

This study has some limitations that should be considered in future research. First of all, the results are based on just one sample and participants were recruited using the internet. Future studies should replicate these results in larger samples and questionnaires should also be collected using more direct methods. Moreover, in the present study we did not ask participants whether they had had previous unpleasant encounters with justice (e.g. experiences of violence). These experiences may have affected their evaluation of the scenarios. Further, in the future other news items and other nationalities for the offenders should be used to confirm the observed results. In particular, other out-group nationalities should be used so as to generalize the present result to any morally excluded out-group. Additionally, the scenarios could be varied so that the culprit and the victim share the same group membership as well. Finally, given the impact of the media in structuring and influencing individual opinions, media exposure should also be taken into account.

Notwithstanding these limitations, the present research project provides novel insights into the analysis of justice in an intergroup context and suggests that the effect of moral inclusion/exclusion processes on the evaluation of justice events should be considered. First, as Hafer and Olson (2003) have stated, research into social justice should reassess the consideration of distributive and procedural justice in light of the issue that the evaluation of justice also depends on the breadth of the moral community people refer to. 
In this sense, the consideration of moral inclusion and exclusion processes might explain why the allocation of goods in a society and the administration of justice and legal proceedings are often unfair and undemocratic. Second, unlike more blatant prejudicial attitudes, moral exclusion processes are both more indirect and more socially accepted (Opotow, 1990; Passini, 2017). That is, the use of moral exclusion strategies may lead to harsher judgments of offenders due to their group membership, without that the evaluator had to face public disapproval. Moreover, moral exclusion processes are psychological mechanisms that serve to maintain the individual's sense of moral integration (Passini, 2013). Individuals may indeed act unfairly in overcoming or minimizing a personal sense of guilt and justifying their own moral conduct and perception of justice. In this sense, it may be relevant to analyze the link between judgments of justice and intrapersonal and social acceptance in considering moral exclusion processes.

The findings of the present study have some practical implications as well. In particular, the issue that a prejudicial evaluation of the events and a narrower sense of justice emerge when people tend to exclude some out-groups from their scope of justice is relevant when considering strategies to reduce and offset the onset of prejudice against minorities. Making people aware of the way in which justice is differentialy applied depending on the people who are being judged could lead people to broaden their scope of justice. In this regard, the educational environment can play an important role in determining the individual's awareness of their sense of justice and in mitigating prejudicial worldviews.

\section{References}

Abrams, D., Randsley de Moura, G., \& Travaglino, G. A. (2013). A double standard when group members behave badly: Transgression credit to ingroup leaders. Journal of Personality and Social Psychology, 105(5), 799-815. https://doi. org/10.1037/a0033600

Bies, R., \& Moag, R. (1986). Interactional justice: Communication criteria of fairness. In R. J. Lewicki, B. H. Sheppard \& M. H. Bazerman (Eds.), Research on negotiations in organizations (pp. 43-55). Greenwich, CT: JAI Press.

Bogardus, E. S. (1933). A social distance scale. Sociology \& Social Research, 17, 265-271..

Deutsch, M. (1985). Distributive justice. New Haven, CT: Yale University Press.

Fontanella, L., Villano, P., \& Di Donato, M. (2016). Attitudes towards Roma people and migrants: a comparison through a Bayesian multidimensional IRT model. Quality \& Quantity, 50(2), 471-490.

Hafer, C. L., Conway, P., Cheung, I., Malyk, D., \& Olson,
J. M. (2012). The relation between people's connection with a target and the perceived importance of justice. Basic and Applied Social Psychology, 34(5), 395-409. https://doi.org/10. 1080/01973533.2012.711693

Hafer, C. L., \& Olson, J. M. (2003). An analysis of empirical research on the scope of justice. Personality and Social Psychology Review, 7(4), 311-323.

Jost, J. T., \& Major, B. (Eds.). (2001). The psychology of legitimacy: Emerging perspectives on ideology, justice, and intergroup relations. Cambridge: Cambridge University Press.

Lima-Nunes, A., Pereira, C. R., \& Correia, I. (2013). Restricting the scope of justice to justify discrimination: The role played by justice perceptions in discrimination against immigrants. European Journal of Social Psychology, 43(7), 627-636.

Lind, E. A., \& Tyler, T. R. (1988). The social psychology of procedural justice. New York, NY: Plenum Press.

Marques, J. M., Yzerbyt, V. Y., \& Leyens, J. P. (1988). The "black sheep effect": Extremity of judgments towards in-group members as a function of group identification. European Journal of Social Psychology, 18(1), 1-16.

Norcini Pala, A., Villano, P., \& Clinton, L. (2017). Attitudes of heterosexual men and women toward HIV negative and positive gay men. Journal of homosexuality, 64(13), 1778-1792.

Opotow, S. (1990). Moral exclusion and injustice: An introduction. Journal of Social Issues, 46(1), 1-20.

Opotow, S. (2008). "Not so much as place to lay our head...": Moral inclusion and exclusion in the American civil war reconstruction. Social Justice Research, 21(1), 26-49.

Passini, S. (2011). Individual responsibilities and moral inclusion in an age of rights. Culture \& Psychology, 17(3), 281-296.

Passini, S. (2013). What do I think of others in relation to myself? Moral identity and moral inclusion in explaining prejudice. Journal of Community \& Applied Social Psychology, 23(3), 261-269.

Passini, S. (2015). Social relations, the financial crisis and human development. In C. Psaltis, A. Gillespie, \& A.-N. Perret-Clermont (Eds.), Social Relations in Human and Societal Development (pp. 194-214). London: Palgrave Macmillan.

Passini, S. (2016). Concern for close or distant others: The distinction between moral identity and moral inclusion. Journal of Moral Education, 45(1), 74-86.

Passini, S. (2017). Subtle prejudice and conformism: The intergroup indifference. International Journal of Psychological Research, 10(1), 25-34.

Passini, S., \& Morselli, D. (2016). Blatant domination and subtle exclusion: The mediation of moral 
inclusion on the relationship between social dominance orientation and prejudice. Personality and Individual Differences, 89, 182-186.

Passini, S., \& Morselli, D. (2017). Construction and validation of the moral inclusion/exclusion of other groups (MIEG) scale. Social Indicators Research, 134(3), 1195-1213.

Passini, S., \& Villano, P. (2013). Judging moral issues in a multicultural society: Moral reasoning and social dominance orientation. Swiss Journal of Psychology, 72(4), 235-239.

Skitka, L. J., Bauman, C. W., \& Mullen, E. (2008). Morality and justice: An expanded theoretical perspective and empirical review. In K. A. Hegtvedt \& J. Clay-Warner (Eds.), Justice (Vol. 25, pp. 1-27). Bingley, UK: Emerald Group Publishing Limited.

Sullivan, D., \& Tifft, L. (2001). Restorative justice: Healing the foundations of our everyday lives. Monsey, NY: Willow Tree Press.

Stephan, W. G., \& Stephan, C. W. (2001). Improving intergroup relations. Thousand Oaks, Calif: Sage Publications.

Tyler, T. R., Boeckmann, R. J., Smith, H. J., \& Huo, Y. J. (1997). Social justice in a diverse society. Boulder: Westview Press.

Van den Bos, K. (2003). On the subjective quality of social justice: the role of affect as information in the psychology of justice judgments. Journal of Personality and Social Psychology, 85(3), 482-498.

Van Dijk, T. A. (2000). New(s) racism: A discourse analytical approach. In S. Cottle (Ed.), Ethnic minorities and the media (pp. 33-49). Buckingham: Open University Press. 